\title{
"DOGGY DOLLY": DESIGN EXPLORATION OF CUSTOMISED MOBILITY DEVICE FOR A HANDICAPPED DOG
}

\author{
Dosun SHIN \\ Arizona State University
}

\begin{abstract}
This paper introduces the research and process of assistive device design for a special 4-year-old dog who lost one of his front left legs due to a gun shot by a policeman on the street. This project involves diverse design activities that include the observation of the 4 dog's daily activities and gait (walking style), data collection and analysis, concept generation, prototyping, and product testing. The primary goal of this project is to design a customised mobility device which enables the dog to walk around with ease and comfort. Mobility, durability, stability, safety, ergonomics, and comfort were the main objectives to make this product successful, and they were tested during the entire design process to reach the goal. This paper illustrates how a design team from The Design School at Arizona State University in the U.S.A. helped the handicapped dog with an assistive device by sharing the challenges, successes and focused ergonomic research on the user experiences of a dog.
\end{abstract}

Keywords: Animal assistive device, handicapped dog, ergonomics, industrial design, prototyping

\section{INTRODUCTION}

Pets have become an important part of our lives and they live with us as family members. In the military, the police department, airport security, and as guides for individuals with disabilities, dogs have been playing a significant role in helping human society. Their impact on our lives is clear and obvious. However, there are a number of disabled dogs that need prosthetics or assistive devices to support their bodies while allowing them to walk around. The American Society for the Prevention of Cruelty to Animals (ASPCA) National Outreach department estimates that more than 5,000 non-profit animal shelters exist in the United States (ASPCA, 2018). According to the Humane Society of the United States, approximately 6.5 million companion animals enter U.S.A. animal shelters nationwide every year. Of those 3.3 million are dogs and 3.2 million are cats. More than half of them that enter shelters are put to sleep because they are sick, old, not adopted, or the shelters do not have enough space. (Pet Statistics, 2018) Handicapped animals are seldom adopted by a new owner and they will most likely be euthanised. Sadly, but honestly, people do not prefer to adopt handicapped animals because most prosthetics are customised and expensive.

This research studies ergonomics and explores new product design and development for a specific dog that makes special attention to local, university, and the international design community. This project involves the research and design of a prosthetic leg, an assistive device, for a special dog who lost one of his front legs due to a gun shot on the street at California in the U.S.A. This dog was adopted by a local non-profit animal rescue and rehabilitation company called Handover Rover in Tempe, Arizona. The owner of the company contacted Prof. Shin, who is an Associate Professor of Industrial Design at ASU and the author of this paper, and introduced a 4-year-old dog, named Big Chuck, an over 100 pound black mastiff. After the first meeting with the owner, Prof. Shin kicked off the project without any hesitation, and created a design team with an industrial design graduate student.

\section{SCOPE AND GOALS}

This research project involves diverse design activities that includes the observation of the dog's daily activities and gait (walking style), data collection and analysis, concept generation, design visualisation, 3-dimensional computer modelling, prototyping, machining, fabricating a fully working product, and 
product testing. The primary goal of this project is to design a prosthetic or an assistive device that will help Chuck (the dog) walk and stand on his own for longer periods of time. Mobility, durability, stability, safety, wearability and comfort are our focus for this project. From an educational standpoint, it will also provide a remarkable opportunity to the student, by working on a meaningful real project, conducting design research, solving a significant problem and generating new product ideas. This research of assistive products to help other handicapped animals is an ongoing activity, that will require multiple semesters and many hours from Prof. Shin and the student to complete. Once the design is completed, there will be an effort to find possible intellectual properties with the design or new mechanisms that could come out as the result. Leading faculty will work towards submitting a grant proposal after the preliminary prototyping tests. Upon completion of this project, our goal is to have a completely usable and functioning product that can be used on a daily basis by Chuck.

\section{PROCESS AND DATA ANALYSIS}

Prototype models have been the best implement that has demonstrated multiple product ideas and functionality and have provided precise feedback on the ergonomics of the dog. Measuring the shape and size of the dog's body is significant, as this directly relates to his comfort. In order to obtain the overall shape and size of the dog's upper body, there were several efforts in measuring. A stuffed animal dog was used to measure the upper body and generate concepts through a series of fibre glass prototypes. These models were tested on the dog to acquire the measurement data and were able to demonstrate the functionality, mobility, stability, ergonomics and comfort.

\subsection{Gait (Walking style)}

This diagram illustrates the sequence of steps and walking style of a four-legged dog. (Foot patterns of doggos, 2017) There are 8 steps to complete 1 round of a foot pattern, and the blue arrows on the diagram represent the time intervals between each step.

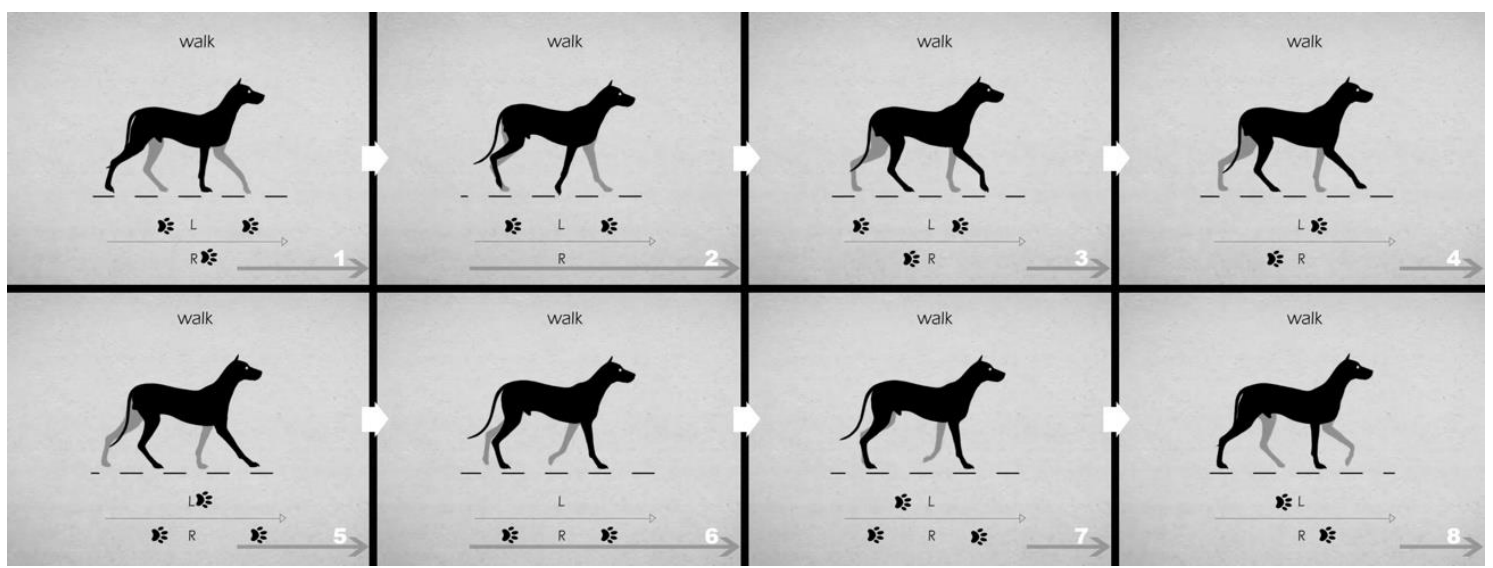

Figure 1. The sequence of steps and walking style (Animated by Stephen Cunnane)

The walking time from step 3 to 4 is same as step 7 to 8 , and they are the shortest. Step 1 to 2 is same as step 5 to 6 and this is longer. The walking time from step 2 to 3 is same as step 6 to 7 , and they are the longest. The lengths of step time are following by the order as shown below.

$$
3(7) \text { to } 4(8)=4(8) \text { to } 5(1)<1(5) \text { to } 2(6)<2(6) \text { to } 3(7)
$$

This animation and time interval analysis provides evidence that a dog walks longer with only one side of legs and steps with the rear leg first.

\subsection{Observation and Analysis}

The team began by observing the dog and collected the Chuck's walking style, and this diagram represents the parameter of his steps with 3 legs and the free walking zone for a prosthetic or wheeled leg. 

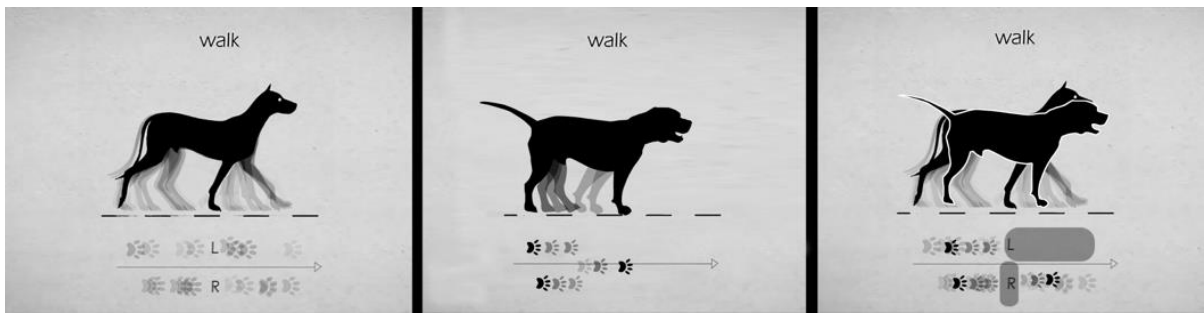

Figure 2. The area of step with 4 legs (left), The area of Chuck's step (middle), Free zone (right)

Chuck's sole front leg steps in the middle of his upper body to help him balance, and the distance of his one step was wider than normal dogs. The images above are showing the area of steps from a normal dog and Chuck. The grey rectangle area on the right image is the "free zone", this zone is clear from intruding or hitting Chuck's other legs and/or feet, providing for the best possible area to place a prosthetic or wheel.
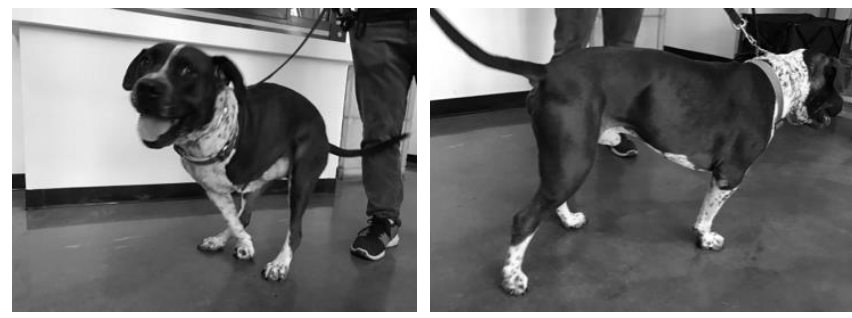

Figure 3. Chuck's walking style with his 3 legs

\subsection{Measurement}

After initial observations, we constructed 3 rough study models that were made out of cardboard, plastic, foam, and plywood that were quickly built to help measure the size of the dog and come up with ideas of how to attach the device to his body and support his weight. These models helped to determine the overall structure of the device and decide design direction. These initial measurements helped us lean towards a wheeled device, rather than a prosthetic leg because of his current body condition. Due to his large weight and body size, we theorised that a wheeled device could help alleviate the pressure and strain put on his front right leg. This could also allow him to walk around with a more fluid motion, compared to a typical prosthetic that could potentially drag on the ground. For this, we made several measurements of his body height, leg length, chest width, and upper/side torso that gave us the basic size parameters for our prototypes that will be used throughout this entire process.
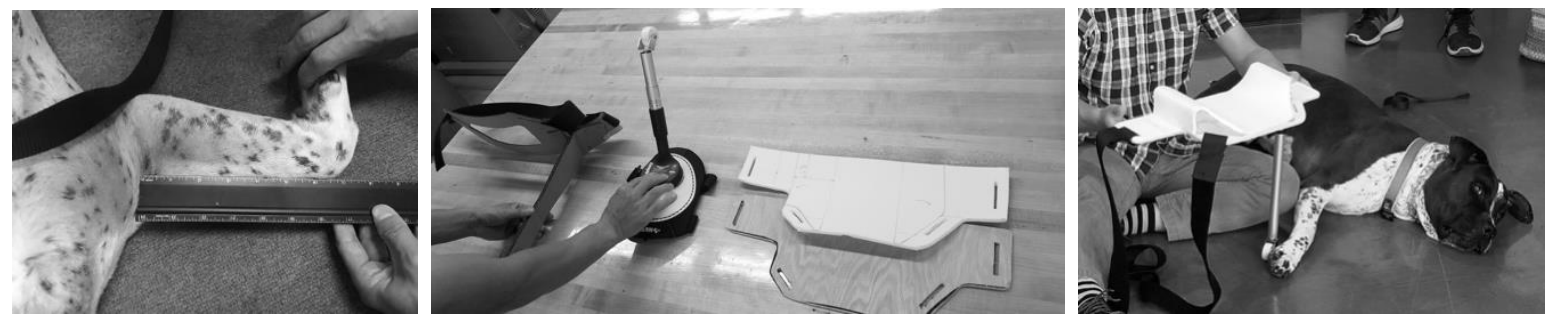

Figure 4. Measurement prototypes

\section{CHALLENGES}

Unfortunately, Chuck doesn't have any bone structure left from his left front leg, due to it being completely removed from surgery. This was the main challenge the team faced, and we needed to find a way to secure the prosthetic safely on his body. All prosthetics that are currently available to purchase require bone structure for the prosthetic to attach or plug into. However, based on the current body condition of Chuck, the team decided to not go with a typical prosthetic type design, but instead we decided to go with a wheeled type of mobility device we called a "dog wheelchair" due to its similar 
functionality to a human wheelchair. We believed this would help improve Chuck's mobility, stability and comfort.

Our next series of prototypes were all "dog wheelchair" style designs. For these concepts we wanted to design an assistive device that Chuck could jump on and off easily, that did not require to be strapped to his body. This would allow Chuck to sit and lie down freely without his owner's assistance. A main challenge we faced was making these devices stable enough to not accidentally tip over, while also providing enough strength to hold his body weight. Also, we were challenged with understanding Chuck's unique walking style (section 2.2), that caused us to modify our designs due to the wheels getting in the way of his feet. Also, we learned that for the wheelchair style design, Chuck's owners will need to train him how to use this device. Thankfully, his owners feel confident that they can train him however, we will need the device to be intuitive enough for him to understand how to use it.

One key difference while preforming measurements, is that dogs don't understand what is happening in the same way human subjects would understand, and Chuck tends to move around a lot while we attempted to make precise measurements. This made it very challenging and led us to make some design decisions based on trial and error. Also, animals are not able to provide the same level of feedback as a human, regarding comfortability and overall effectiveness of the device. There were several attempts the team explored to measure the chest size of the dog. A large stuffed animal dog provided the overall shape of the upper body, and the shape was cast with fiberglass and liquid resin. It was a challenge to measure the accurate size and shape of the dog's upper body, and the team produced a series of different size chest cups, followed by the repetition of measurements.
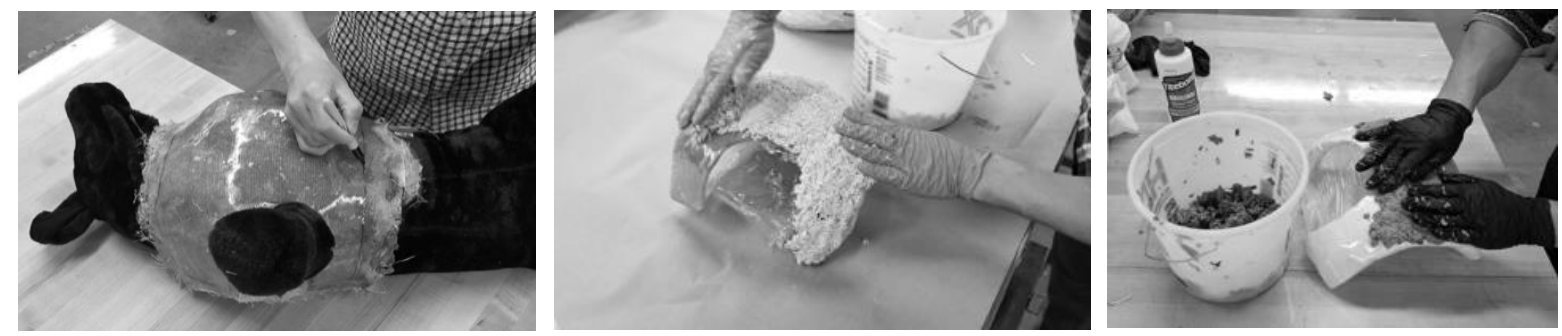

Chest cup casted from the stuffed dog (left) Second modified chest cup made from the first cup (middle) Third modified chest cup made from second cup (right)

Figure 5. A series of chest cups created for accurate measurement

Another challenge we faced was not having the dog readily available when making design decisions and measurements. This proved to be difficult because our team had to rely completely on notes, photographs, and videos when making decisions. Not being able to have instant feedback on our design directions sometimes slowed down the process and caused us to make mistakes. However, in generally our client was readily available to meet often within about 3 to 5 day notice. Even though this doesn't seem like a long period of time, it definitely took longer to test possible solutions.

\section{PROTOTYPE TESTS}

The primary purpose of the prototype tests was to check the dog's upper body size and shape with the chest cup and to exam if he can rely on the cup and walk with one front leg. The inaccurate size of first cup and unsecured one central leg with two wheels resulted in the failure of test from the dog, but provided valuable data and feedback regarding to the dimensions and his reliance on the device. Second chest cup was casted on the top of the first cup using shredded paper with glue to increase the size and shape. Then, several layers of fibre glass with resin were applied on the surface to harden the cup. It was a huge improvement in terms of the dimensions and stability with 3 legs. The height was somewhat short, and the dog was not able to put his upper body on the cup, and he was still trying to stand with his one front leg. The third prototype was built following the same building process, but clay was used to enlarge the base mould. A soft pad material was added inside of the cup to provide better comfort and the one central height-adjustable leg with three wheels was able to provide some cushion and reduce the cumbersome structure that can be the obstacles from his walking parameter. The dog was able to put his upper body on the chest cup and walk several steps, but he still didn't trust the device. 
Table 1. Summary of prototype tests

\begin{tabular}{|c|c|c|c|}
\hline Test categories & 1 & 2 & 3 \\
\hline Prototype & One leg with two wheels & Three legs with four wheels & One leg with three wheels \\
\hline Size and shape & $\begin{array}{l}\text { Chest cup was somewhat tight and } \\
\text { needed a wider opening on the front } \\
\text { leg. Overall shape was close, but front } \\
\text { part of cup had some empty gap. }\end{array}$ & $\begin{array}{l}\text { Chest cup was still a little tight. } \\
\text { Front centre wheel was a little } \\
\text { close to his front paw. }\end{array}$ & $\begin{array}{l}\text { Largest chest cup. Centre post } \\
\text { centres his body over the wheels. } \\
\text { Front wheel rotates to help him } \\
\text { turn. }\end{array}$ \\
\hline Height & 1.5 inch short & $1 / 2$ inch short & $\begin{array}{l}\text { Replaceable centre post to adjust } \\
\text { height }\end{array}$ \\
\hline Stability & $\begin{array}{l}\text { One leg with two wheels didn't stand } \\
\text { and was not able to support his upper } \\
\text { body. }\end{array}$ & $\begin{array}{l}\text { Much more stable. Still possible to } \\
\text { accidentally tip over. }\end{array}$ & $\begin{array}{l}\text { Welded wheel construction. } \\
\text { Possible to be tipped over due to } \\
\text { wheel configuration. }\end{array}$ \\
\hline Mobility & Wheels seemed small and too slick. & $\begin{array}{l}\text { Larger wheels. Rolled straight } \\
\text { well but was difficult to turn. }\end{array}$ & $\begin{array}{l}\text { Increased mobility. Rotating } \\
\text { wheel can sometimes be hard to } \\
\text { turn. }\end{array}$ \\
\hline Safety & $\begin{array}{l}\text { Cup was strong enough and didn't } \\
\text { make any body injury, but the whole } \\
\text { device was not secured on the body. }\end{array}$ & $\begin{array}{l}\text { Cup was strong and didn't make } \\
\text { any body injury. Wheels could hit } \\
\text { his paws if not careful. }\end{array}$ & $\begin{array}{l}\text { Cup is very strong. Might need } \\
\text { straps to prevent cup from } \\
\text { rubbing. }\end{array}$ \\
\hline Comfort & $\begin{array}{l}\text { Cup didn't fit well and somewhat } \\
\text { tight. }\end{array}$ & $\begin{array}{l}\text { Additional padding needed on cup } \\
\text { to protect chest rubbing. }\end{array}$ & $\begin{array}{l}\text { Additional padding added and } \\
\text { provided better comfort. }\end{array}$ \\
\hline Reliance & $\begin{array}{l}\text { The dog didn't trust the cup and didn't } \\
\text { put his upper body on the cup. }\end{array}$ & $\begin{array}{l}\text { The dog didn't trust device and } \\
\text { would need training to use. }\end{array}$ & $\begin{array}{l}\text { Training is still needed. Centre } \\
\text { wheel joint needs to be stronger. }\end{array}$ \\
\hline Challenges & $\begin{array}{l}\text { Unable to secure the device on his } \\
\text { body because of his slippery skin and } \\
\text { short device leg. }\end{array}$ & $\begin{array}{l}\text { Low turn radius. Chest cup needs } \\
\text { to be larger to fit around right leg. }\end{array}$ & $\begin{array}{l}\text { Strengthening centre joint. } \\
\text { Rotating wheel can be difficult to } \\
\text { manoeuvre. }\end{array}$ \\
\hline
\end{tabular}

\section{LEARNING AND REFINMENT}

For this project, we gained a new level of understanding of how dogs walk compared to our disabled dog. We also improved our understanding of the dog's anatomy, which has been essential to the success of this project. Also, we gained a new appreciation and knowledge for the complexity of designing animal prosthetics. Animal and human prosthetics alike can require multiple levels of expertise that focus on everything from anatomy, physiology, psychology and design. Since we only have expertise in design, it was very important to research all these areas and reach out to other professionals for advice. Our next step in the prototyping/ research process will involve the collaboration with a local veterinarian, who will examine Chuck and provide insights on his anatomy, giving us feedback on whether our design will put pressure on his heart or other organs. This is obviously very important as we want to make the device as safe as possible.

Further development and refinement will continue to be made on our prototype(s) with a goal of designing a functional mobility device by May 2019. After Chuck becomes comfortable and successful with using the device, we will start the next phase of the project which will focus on improving the design aesthetics.

\section{DESIGN FOR COMMUNITY}

Community engagement is one of the critical commitments and responsibilities that ASU and The Herberger Institute for Design and the Arts have been promoting. Engaging with our local community on design projects has proven to be very important and even essential to understanding the many needs and desires of our community. In doing so, it provides an opportunity for students and faculty to engage with the community on real issues, while also providing the community a resource for solutions and knowledge. This collaboration has proven to be very successful and beneficial to everyone involved. 
Recently, Arizona State Press (ASU Newspaper) and Arizona local news (3TV \& CBS 5) channels interviewed Prof. Shin and highlighted this research and design project. These media stories brought attention to the project which has helped with recognition and support from ASU and our community. This project was also highlighted in the IDSA (Industrial Designers Society of America) Newsletter in November of 2018.

\section{PROJECT BASED DESIGN EDUCATION}

This project has been a completely hands-on process, that provided the student with real world experience. This type of education has shown to be very beneficial to the student for many reasons, especially being able to meet directly with the client and dog on several occasions. This allowed the student to observe, listen, and ask questions and get direct feedback, that has been applied to our design. Throughout this process, our team also made many mistakes and failures, that lead us to make changes to the design. This trial and error method teach students to think critically and solve diverse problems. Many times, in a typical classroom setting this diversity of challenges can be overlooked, due to not having the same type of interaction with the client. Thankfully, our client has been very responsive and accommodating by providing several opportunities to work directly with the dog.

\section{FUTURE STUDY}

The future of this project will involve creating additional prototypes of other possible design directions. One area we plan to explore is creating a prosthetic type design that will strap onto the dog and use a flexible spring material for the foot of the device. Our hope is when the dog steps forward with the spring foot, he will bounce off the spring to help propel him forward. This style of design will also force the dog to put his body weight on the device, which will hopefully allow him to trust the product. The downside to this style design compared to the wheelchair style is that the owner will have to continually take it on and off. This could become problematic, as Chuck is used to sitting and lying down very frequently. As mentioned earlier, a benefit to the wheelchair style design would allow Chuck to jump on and off the device as much as he needed. However, this design style will likely require Chuck to have more training and would need to function without the wheels being obtrusive to his other legs/ paws.

We currently submitted an internal Research Investment grant proposal to ASU to help provide additional funding for research and prototype testing, and the review is being processed. Once we complete the prototype tests that verify the functionally, durability and stability, we will apply for a larger grant along with the possible industry partnership. We have started a conversation with large companies like PetSmart in hopes to receive additional funding and support. This partnership could potentially open up opportunities to develop or manufacture this product for other dogs or animals like Chuck.

\section{CONCLUSIONS}

Design is a powerful force in our lives, whether we are always aware of it or not. Design can be inspiring, empowering, and at times even life changing. This project was able to bring two groups of people together in the community to accomplish one goal: to improve the mobility and life of a very special dog who deserves everything through an innovative design that will make a substantial contribution, not only to our local pet owners, but also to our larger community. Furthermore, the educational and realworld experiences of projects like this one provide students the skills they needed to be successful upon graduation.

\section{REFERENCES}

[1] http://veterinarymedicine.dvm360.com/animal-sheltering-united-states-yesterday-today-andtomorrow.

[2] https://www.aspca.org/animal-homelessness/shelter-intake-and-surrender/pet-statistics.

[3] https://imgur.com/gallery/aVQnv. 